\title{
Pandemi Döneminde Beden Eğitimi ve Spor Yüksekokulu Öğrencilerinin Beslenme Alışkanlıkları ve Fiziksel Aktivite Düzeylerinin Belirlenmesi
}

\author{
DOI: $10.26466 /$ opus. 862585
}

$*$

\begin{abstract}
Ramazan Erdoğan *
* Dr. Öğr. Üyesi, Bitlis Eren Üniversitesi Beden Eğitimi ve Spor Yüksekokulu, Bitlis/Türkiye E-Posta: ramaznerdogan@hotmail.com

ORCID:

$\ddot{O} z$
\end{abstract}

Korona virüsün dünyada yayılımının artması neticesinde, Türkiye'de günlük yaşamda değişikliklere neden olarak, sosyal mesafeyle birlikte toplumu izole olmaya yönlendirmiştir. Alnnan bu önlemler kişilerin yaşam tarzlarım etkilemektedir. Bu araştırma beden eğitimi ve spor yüksekokulu öğrencilerinin pandemi sürecinde beslenme alışkanlıkları ve fiziksel aktivite düzeylerini belirlemek amacıyla yapılmıştır. Araştırmaya Bitlis Eren Üniversitesi (125 kişi) ve Van Yüzüncü yıl Üniversitesi (106 kişi) beden eğitimi spor yüksekokulunda öğrenim gören 231 (93 Kadın, 138 Erkek) gönüllü öğrenci katılmıştır. Veri toplama aracı olarak katılımcıların demografik bilgilerini, beslenme alışkanlıklarını ve fiziksel aktivite düzeylerinin sorgulandığı online bir anket formu uygulanmıştır. Veriler SPSS paket programında analiz edildi ve anlamlılık $p<0,05$ olarak kabul edilmiştir. Araştırma sonuçlarına göre beden eğitimi ve spor yüksekokulu öğrencilerinin, \%45,5'inin beslenme alışkanlıklarında değ̌işiklikler olduğu, \%50,6'sının günde iki ana öğ̈̈n tükettikleri, \%63,6'sinın düzenli olarak kahvaltı yaptı̆̆ı, en fazla atlanan ana ö̆̆̈̈nün \%40,3 ile öğlen yemeği olduğu, \%26'sının stres sebebiyle öğ ün atladı̆̆ın, ara öğünlerde \%40,3 ile en fazla kek/kurabiye/bisküvi gibi yiyecekler tükettiği, \%53,2'sinin günlük sivı tüketim miktarmin azaldı̆̆ ve \%36,4'ünün günlük olarak 1,5 litre sivı tükettiğini ve $\% 62,3$ 'ünün beslenme eğitimi almadıkları, \%60,2'sinin beden eğitimi ve spor öğretmenliği bölümünde okudukları belirlenmiştir. Araştırma grubunun \%67,5'inin düzenli olarak bir fiziksel aktivite yapmadığgl, \%51,9'unun haftada iki gün egzersiz yaptığı, \%48,1'inin vücut ağırlı̆̆ında artış olduğu, \%68,8'inin ise fiziksel aktivitelerini evde yaptığ tespit edilmiştir. araştırma grubunda yer alan beden eğitimi ve spor yüksekokulu öğrencilerinin beslenme alışkanlıklarında değişiklikler olduğu ve fiziksel aktivite seviyelerinin azaldığı görülmüştür. Bu bağlamda pandemi döneminde sağhlklı beslenmenin yanı sıra evde yapılacak fiziksel aktivitelerin teşvik edilmesi bireylerin sağglılarını olumlu yönde katkı sağlayacağı düşünülmektedir.

Anahtar Kelimeler: Pandemi, Beslenme Alışkanlıkları, Fiziksel Aktivite, Covid-19, Öğrenci 


\title{
Determination of The Nutritional Habits and Physical Activity Levels of The Students of The School of Physical Education and Sport During the Pandemic Period \\ *
}

\begin{abstract}
As a result of the increasing spread of corona virus around the world, daily life in Turkey has changed, forcing society to be isolated along with social distances. Such measures are affecting people's lifestyles. This research was conducted to determine the nutritional habits and physical activity levels of students at the School of Physical Education and Sport during the pandemic. A total of 231 (93 female, 138 male) volunteer students from Bitlis Eren University (125 persons) and Van Yüzüncü Yıl University (106 persons) participated in the study. An online questionnaire was used as a data collection tool to question participants' demographic information, nutritional habits and levels of physical activity. The data were analyzed in the SPSS package program and the significance was accepted as $p<0.05$. According to the results of the research, it was determined that: $45.5 \%$ of the students of the school of physical education and sports had changes in their eating habits, $50.6 \%$ of the students consumed two main meals a day, 63,6\% of the students regularly have breakfast, lunch is the most skipped main meal with 40.3\%, 26\% of the students skip meals due to stress, the most consumed foods as snacks are cakes / cookies / biscuits with $40.3 \%, 53,2 \%$ of the students reduce daily liquid consumption and $36,4 \%$ of the students consume 1.5 liters of liquid daily and $62,3 \%$ of the students did not receive nutrition education, $60,2 \%$ of the students are study in physical education and sports teaching department. It was found that $67.5 \%$ of the research group did not do regular physical activity, $51.9 \%$ exercised two days a week, $48.1 \%$ increased body weight, and $68.8 \%$ did physical activity at home. Physical education and sports students in the research group underwent changes in eating habits and reduced levels of physical activity. In this context, it is believed that promoting healthy eating and physical activity at home during the pandemic period will contribute positively to the health of individuals.
\end{abstract}

Keywords: Pandemic, Nutrition Habits, Physical Activity, Covid-19, Student 


\section{Giriş}

Dünya Sağlık Örgütü'nün (DSÖ) pandemi olarak kabul ettiği koronavirüs hastalığı (COVID-19) tüm dünyada olduğu gibi ülkemizde de hayatı ciddi derecede etkileyen önemli bir halk sağlığı sorunudur. Salgının yayılımının kontrol edilmesine yönelik alınan önlemlerle beraber beslenme alışkanlıkları, fiziksel aktivite düzeyleri, tüketici davranışları, eğitim-öğretim yöntemleri ve gündelik yaşam hızla değişmektedir (Gençalp, 2020). COVID-19 salgını sırasında immün sistemi desteklemek için bireylerin sorumluluğu sağlıklı bir yaşam tarzı seçmek, meyve ve sebzelerden zengin beslenmek, boş zamanlarında egzersiz yapmak, sağlıklı vücut ağırlığını korumaya çalışmak ve yeterli sürede uyumak olarak belirtilmiştir (Naja ve Hamadeh, 2020). Bunlara ek olarak sigara ve alkolden kaçınma ve stresi en aza indirme de önerilmektedir (Harvard Health Publishing Harvard Medical School, 2020).

Sağlıklı yaşam biçimi kavramı, kişilerin sağlığını etkileyebileceği düşünülen akla gelebilecek tüm davranışlarını kontrol edebilmesi, günlük aktivitelerini düzenlemede kendi yaşam felsefesi içinde sağlık yapısına uygun davranış hedefleri seçerek hayatında düzenlemeler yapılması olarak tanımlanırken sağlıklı yaşam biçimi davranışları, bireylerin sağ lığını etkileyebilecek tüm davranışları üzerinde kontrol sahibi olmaları ve günlük aktivitelerinde sağlıklarını yükseltmeye yönelik davranışları seçerek uygulamalarıdır (Özkan, 2017; Tambağ, 2011). Sağlıklı yaşam biçimi davranışları veya aktiviteleri kendini gerçekleştirme, sağlik sorumluluğu, beslenme, kişiler arası destek stres yöntemini ve egzersiz ya da fiziksel aktiviteyi içermektedir (Özkan, 2020).

Pandemi ortamında veya sosyal izolasyon koşullarında bireylerde özellikle depresyon, kaygı bozukluğu ve artmış stres seviyeleri görülebilmektedir (Brooks, Webster, Smith, Woodland, Wessely, Greenberg ve Rubin, 2020; Courtin ve Knapp, 2017; Tang, Hu, Hu, Jin, Wang, Xie ve Xu, 2020). Yapılan çalışmalarda depresyon, kaygı ve artmış stres seviyelerinin, diyet seçimlerinin değişmesine neden olduğu gözlemlenmiştir (Arce, Michopoulos, Shepard, Ha, ve Wilson 2010; Flaskerud, 2015; Vermeulen, Stronks, Snijder, Schene, Lok, de Vries, ve Nicolaou, 2017). Yüksek psikolojik stres altındaki kişilerde özellikle duygusal yeme davranışı gözlemlenmekte ve bu bireyler yüksek yağ ve yüksek şeker içeriğine sahip olan stresi azaltan besinlere eğilim göstermektedir (Jayne, Ayala, Karl, Deschamps,McGraw, O'Connor ve 
Cole, 2020). Bu tarz içeriklere sahip diyetlerin obeziteye neden olduğu ve bağışıklık sistemini kötü etkilediği de bilinmektedir (Christ, Lauterbach ve Latz, 2019; de Heredia,Gómez-Martínez ve Marcos, 2012). Fiziksel aktivitenin de kilo kontrolünde dolayısıyla sağlığın korunmasında çok önemli bir rol oynadığı bilinen bir gerçektir (Swift, Johannsen, Lavie,Earnest ve Church, 2014). Bu bağlamda çocukluklara erken yaşlarda kazandırılacak düzenli fiziksel aktivite ve egzersizi alışkanlığı, bireysel ve toplumsal sağll$\breve{g} ı$ ızın korunması ve ileride karşılaşılacak sağlık tehditlerinin azaltılması, ortadan kaldırılması ve sağlı̆ın korunması anlamında çok önemlidir. Buradan yola çıkarak toplumu oluşturan bireylerin sağlıklı olması, sağlıklı yaşam davranışı sergilemesi ve yaşam kalitesini artırabilmesi için fiziksel aktivitesini artırması ön koşuldur. Toplumu oluşturan kişilerin sağlıklı bir yaşamın temellerini oluşturabilmesi için öğrencilik yıllarında bireylerin fiziksel aktiviteyi hayatının temellerinden birisi haline getirmesi ileriki yıllarda kalıcı bir etki bırakacaktır. Bu anlamda öğrencilerin sağlıklı yaşam biçimi davranışlarını algılaması ve hayatında uygulaması kişilere sağlıklı bir yaşam açısının yanı sıra toplumsal sağlığıda geliştirmiş olacaktır (Özkan, 2020).

Üniversite öğrencileri de ileriye yönelik beslenme alışkanlıklarının yerleştiği kritik bir dönemde bulunmaktadırlar. Üniversite eğitimi ile birlikte aktif spor yaşamları da devam eden beden eğitimi ve spor yüksekokulu öğrencilerinin, vücut gereksinimlerine göre dengeli ve düzenli olarak öğün atlamadan beslenmeleri, gerek sağlıklı yaşam açısından, gerekse eğitim ve spor yaşamındaki başarıları bakımından son derece önem taşıyacaktır (Yildirim, Yıldırım ve Tortopve Poyraz, 2011). Bu bağlamda bu araştırma, beden eğitimi ve spor yüksekokulu öğrencilerinin pandemi döneminde beslenme alışkanlıklarını ve fiziksel aktivite düzeylerini tespit etmek amacıyla yapılmıştır.

\section{Gereç ve Yöntem}

Araştırma Bitlis Eren Üniversitesi Girişimsel Olmayan Etik Kurulundan etik kurul onayı alınmıştır (2020/12-III-IV).

\section{Araştırma Grubu}

Araştırma grubunu Bitlis Eren Üniversitesi (125 kişi) ile Van Yüzüncü Y1l Üniversitesi (106 kişi) Beden Eğitimi ve Spor Yüksekokulunda öğrenim 
gören yaş ortalaması 20,26ะ1,34 yıl olan 231 (93 Kadın, 138 Erkek) gönüllü öğrenci oluşturmuştur. Araştırma veri toplama tekniklerinden online anket yöntemiyle gerçekleştirilmiştir.

\section{Veri Toplama Araçları}

Araştırma grubunda yer alan öğrencilere (231 kişi) çalışmanın amacı açıklanarak araştırmaya katılmayı kabul eden katılımcılardan veriler anket yöntemi kullanılarak elde edilmiştir. Araştırmada verilerin elde edilmesinde katılımcıların demografik bilgilerini belirlemek amacıyla "Kişisel Bilgi Formu" ve sağlıklı yaşam biçimlerini belirlemek için ise Yücel (2015) tarafından "Sağlık Çalışanlarının Beslenme Alışkanlıkları ve Beslenme Bilgi Düzeylerinin İncelenmesini" amaçlayan anket ile "Uluslararası Fiziksel Aktivite Anketi" kısa formu alanında uzman dört kişinin görüşü alınarak araştırmanın amacına yönelik uyarlanmış olup verilerin elde edilmesi sürecinde katılımcılara uygulanmıştır. Araştırmada kullanılan anket sorularının geçerlilik güvenirliliği test edilmiş olup KMO değeri .909, Crombach alpha değeri ise .967 bulunmuştur.

MET (Metabolik Eşdeğerlilik) Hesaplama

$1 \mathrm{MET}=3.5 \mathrm{ml} / \mathrm{kg} / \mathrm{dk}$ oksijen tüketimi

METx3.5xağ $1 r l \mathrm{lk}(\mathrm{kg}) / 200=\ldots \mathrm{kcal} / \mathrm{dk}$.

Fiziksel aktivite skoruna göre katılımcların fiziksel aktivite düzeyleri "düşük, orta ve yüksek" biçiminde sınıflandırılmıştır (Devran ve Saka, 2019):

(3) $<3$ MET hafif şiddetli aktivite,

(2) 3-6 MET orta şiddetli aktivite,

(2) $>6$ MET yüksek şiddetli aktivite

\section{Verilerin Analizi}

Araştırmada elde edilen veriler SPSS istatistik paket programından kullanılmıştır. Araştırma grubunun demografik bilgileri, beslenme alışkanlıkları ve fiziksel aktivite düzeyleri "aritmetik ortalama, yüzde, frekans" istatistikleri yardımıyla özetlenmiştir. Verilerin normallik analizi için "KolmogorovSmirnov" testinden faydalanılmıştır. Normal dağılım gösterdiği belirlenen verilere grup içi karşlaş̧tırılmalar için İndependent Samples t ve One-Way Anova testi uygulanmıştır. Anlamlılık $\mathrm{p}<0,05$ olarak kabul edilmiştir. 


\section{Bulgular}

\section{Pandemi Dönemi Beden Eğitimi ve Spor Yüksekokulu Öğrencilerinin Beslenme Alışkanlıkları ve Fiziksel Aktivite Düzeyleri}

Tablo.1. Beden Ĕ̆itimi ve Spor Yüksekokulu Öğrencilerine Ait Demografik Bilgiler

\begin{tabular}{|c|c|c|c|}
\hline & & Frekans & Yüzde (\%) \\
\hline \multirow[t]{2}{*}{ Cinsiyet } & Kadın & 93 & 40,3 \\
\hline & Erkek & 138 & 59,7 \\
\hline \multirow[b]{2}{*}{ Medeni Durum } & Evli & 6 & 2,6 \\
\hline & Bekâr & 225 & 97,4 \\
\hline \multirow{4}{*}{ Boy } & $150-160$ & 53 & 22,9 \\
\hline & $161-170$ & 60 & 26 \\
\hline & $171-180$ & 85 & 36,8 \\
\hline & $181-190$ & 33 & 14,3 \\
\hline \multirow{3}{*}{ Kilo } & $45-60$ & 94 & 40,7 \\
\hline & $61-75$ & 104 & 45 \\
\hline & $76-90$ & 33 & 14,3 \\
\hline \multirow{2}{*}{ Üniversiteniz } & Bitlis Eren Üniversitesi & 125 & 54,1 \\
\hline & Van Yüzüncü Yil Üniversitesi & 106 & 45,9 \\
\hline \multirow{2}{*}{ Bölümünüz } & Beden Eğitimi ve Spor Ö ğretmenliği & 139 & 60,2 \\
\hline & Antrenörlük Eğitimi & 92 & 39,8 \\
\hline \multirow{5}{*}{ Gelir Durumu } & $2001-3000$ & 84 & 36,4 \\
\hline & $3001-4000$ & 60 & 26 \\
\hline & $4001-5000$ & 33 & 14,3 \\
\hline & $5001-6000$ & 24 & 10,4 \\
\hline & 6001 ve üzeri & 30 & 13 \\
\hline \multirow{2}{*}{ Beslenme Eğitimi } & Evet & 87 & 37,7 \\
\hline & Hayır & 144 & 62,3 \\
\hline \multirow{2}{*}{ Kronik Hastalık } & Evet & - & - \\
\hline & Hayır & 231 & 100 \\
\hline
\end{tabular}

Tablo 1 değerlendirildiğinde araştırma grubunda yer alan öğrencilerin; cinsiyet, medeni durum, boy, kilo, üniversite, bölümü ve gelir durumu sırasıyla; \%59,7'si erkek, \%40,3'ü kadın olduğu,\%97,4'ünün bekâr olduğu, 85 kişinin 171-180 cm, 60 kişinin 161-170 cm, 53 kişinin 150-160 cm, 33 kişinin 181-190 cm olduğu, 104 kişinin 61-75 kg, 94 kişinin 45-60 kg, 33 kişinin 76-90 kg olduğu, 84 kişinin 2001-3000 TL, 60 kişinin 3001-4000 TL, 33 kişinin 40015000 TL, 24 kişinin 5001-6000 TL ve 30 kişinin 6001 TL ve üzeri gelir durumuna sahip olduğu belirlenmiştir. Katılımcıların herhangi bir kronik rahatsızlığının olmadığı, \%62,3'ünün beslenme eğitimi almadıkları, \%60,2'sinin beden eğitimi ve spor öğretmenliği bölümünde okudukları tespit edilmiştir. 
Tablo 2. Beden Eğitimi ve Spor Yüksekokulu Öğrencilerinin MET ve BKİ Değerleri

\begin{tabular}{lll}
\hline Değişken & $\mathbf{X}$ & Ss \\
\hline MET & 1,11 &, 18 \\
\hline BKI & 22,04 & 3,55 \\
\hline
\end{tabular}

Tablo 2 incelendiğinde araştırma grubunun MET değerleri ortalaması $1,11 \pm, 18$ olduğu, BKİ değerleri ortalaması 22,04 $\pm 3,55$ olduğu belirlenmiştir.

Tablo 3. Beden Ĕ̆itimi ve Spor Yüksekokulu Öğrencilerinin Beslenme Bilgi Düzeyleri

\begin{tabular}{|c|c|c|c|}
\hline & & Frekans & Yüzde (\%) \\
\hline \multirow{3}{*}{$\begin{array}{l}\text { Pandemi Döneminde Beslenme } \\
\text { Alışkanlığında Değişiklik Oldu } \\
\text { mu? }\end{array}$} & Evet & 105 & 45,5 \\
\hline & Hayır & 90 & 39 \\
\hline & Kismen & 36 & 15,6 \\
\hline \multirow{2}{*}{$\begin{array}{l}\text { Düzenli olarak kahvaltı yapıyor } \\
\text { musunuz? }\end{array}$} & Evet & 147 & 63,6 \\
\hline & Hayır & 84 & 36,4 \\
\hline \multirow{2}{*}{$\begin{array}{l}\text { Günlük ana öğün sayısında } \\
\text { değişiklik oldu mu? }\end{array}$} & Evet & 126 & 54,5 \\
\hline & Hayır & 105 & 45,5 \\
\hline \multirow{4}{*}{ Günlük ana öğün sayısı } & 1 öğün & - & - \\
\hline & 2 öğün & 117 & 50,6 \\
\hline & 3 öğün & 75 & 32,5 \\
\hline & Daha fazla & 39 & 16,9 \\
\hline \multirow[t]{4}{*}{ Gün içerisinde atlanılan ana öğün } & Kahvaltı & 48 & 20,8 \\
\hline & Öğlen & 93 & 40,3 \\
\hline & Akşam & 39 & 16,9 \\
\hline & Öğün atlamıorum & 51 & 22,1 \\
\hline \multirow{6}{*}{ Öğün atlama nedenleri } & Beslenme alışkanlığındaki değişiklikler & 27 & 11,7 \\
\hline & Canım istemediği için & 33 & 14,3 \\
\hline & Vücut ağırlığındaki artış & 30 & 13 \\
\hline & Stres & 60 & 26 \\
\hline & Uyku düzenindeki değişiklikler & 48 & 20,8 \\
\hline & Öğün atlamiyorum & 33 & 14,3 \\
\hline \multirow{3}{*}{$\begin{array}{l}\text { Ara öğünde tükettiğiniz yiye- } \\
\text { cek/içecek türünde değişim oldu mu? }\end{array}$} & Evet & 93 & 40,3 \\
\hline & Hayır & 87 & 37,7 \\
\hline & Kismen & 51 & 22,1 \\
\hline \multirow{6}{*}{$\begin{array}{l}\text { Öğün aralarında en sık tüketilen } \\
\text { yiyecek/içecek türleri }\end{array}$} & Gazlı/Asitli içecekler & 27 & 11,7 \\
\hline & Meyve suyu vb. & 33 & 14,3 \\
\hline & Kek/Kurabiye/Bisküvi & 93 & 40,3 \\
\hline & Şekerleme/Çikolata vb. & 33 & 14,3 \\
\hline & Meyve/Kuru meyve vb. & 27 & 11,7 \\
\hline & Cips/Çerez vb. & 18 & 7,8 \\
\hline \multirow{3}{*}{$\begin{array}{l}\text { Günlük sıvı tüketiminde } \\
\text { değişim oldu mu? }\end{array}$} & Artt & 57 & 24,7 \\
\hline & Azald 1 & 123 & 53,2 \\
\hline & Değişmedi & 51 & 22,1 \\
\hline
\end{tabular}


Günlük su tüketimi

\begin{tabular}{lll}
\hline 1 litre ve altı & 69 & 29,9 \\
\hline 1,5 litre & 84 & 36,4 \\
\hline 2 litre & 45 & 19,5 \\
\hline 2,5 litre ve üzeri & 33 & 14,3
\end{tabular}

Tablo 3 incelendiğinde araştırma grubunun \%45,5'inin beslenme alışkanlıklarında değişiklikler olduğunu, \%50,6'sının günde iki ana öğün tükettiklerini, \%63,6'sının düzenli olarak kahvaltı yaptığını, en fazla atlanan ana öğünün \%40,3 ile öğlen yemeği olduğu, \%26'sının stres sebebiyle ögün atladığını, ara öğünlerde \%40,3 ile en fazla kek/kurabiye/bisküvi gibi yiyecekler tükettiğini, \%53,2'sinin günlük sıvı tüketim miktarının azaldığını ve \%36,4'ünün günlük olarak 1,5 litre sıvı tükettikleri belirlenmiştir.

Tablo 4. Beden Eğitimi ve Spor Yüksekokulu Öğrencilerinin Fiziksel Aktivite Düzeyleri

\begin{tabular}{|c|c|c|c|}
\hline & & Frekans & Yüzde (\%) \\
\hline \multirow{3}{*}{$\begin{array}{l}\text { Düzenli olarak fiziksel aktivite } \\
\text { yapıyor musunuz? }\end{array}$} & Evet & 39 & 16,9 \\
\hline & Hayır & 156 & 67,5 \\
\hline & Kismen & 36 & 15,6 \\
\hline \multirow{4}{*}{$\begin{array}{l}\text { Haftada kaç gün egzersiz } \\
\text { yapıyorsunuz?? }\end{array}$} & 1gün & 39 & 16,9 \\
\hline & 2 gün & 120 & 51,9 \\
\hline & 3 gün & 45 & 19,5 \\
\hline & 4 gün ve üzeri & 27 & 11,7 \\
\hline \multirow{3}{*}{$\begin{array}{l}\text { Fiziksel aktivite yapma durumu- } \\
\text { nuzda olumsuz yönde değişim } \\
\text { oldu mu? }\end{array}$} & Evet & 87 & 37,7 \\
\hline & Hayır & 99 & 42,9 \\
\hline & Kismen & 45 & 19,5 \\
\hline \multirow{4}{*}{$\begin{array}{l}\text { Fiziksel aktivitelerinizi nerede } \\
\text { yapıyorsunuz? }\end{array}$} & Evde & 159 & 68,8 \\
\hline & Koşu/Yürüyüş Alanları & 36 & 15,6 \\
\hline & Belediyenin Spor Alanları & 24 & 10,4 \\
\hline & Spor Salonları & 12 & 5,2 \\
\hline \multirow{3}{*}{$\begin{array}{l}\text { Evde yapılan egzersizlerin yaralı } \\
\text { olduğuna inanıyor musunuz? }\end{array}$} & Evet & 69 & 29,9 \\
\hline & Hayır & 108 & 46,8 \\
\hline & Kismen & 54 & 23,4 \\
\hline \multirow{3}{*}{$\begin{array}{l}\text { Devletin Evde Kal Projesi spor } \\
\text { yapmanızı etkiledi mi? }\end{array}$} & Evet & 69 & 29,9 \\
\hline & Hayır & 102 & 44,2 \\
\hline & Kismen & 60 & 26 \\
\hline \multirow{3}{*}{$\begin{array}{l}\text { Vücut ağırlığınızda değişim } \\
\text { oldu mu? }\end{array}$} & Arttı & 111 & 48,1 \\
\hline & Azaldı & 63 & 27,3 \\
\hline & Değişmedi & 57 & 24,7 \\
\hline $\begin{array}{l}\text { Haftada kaç saat/dakika egzersiz } \\
\text { yapıyorsunuz }\end{array}$ & Dakika/ortalama & 60,97 & \\
\hline
\end{tabular}


Tablo 4 incelendiğinde araştırma grubunun, \%67,5'inin düzenli olarak bir fiziksel aktivite yapmadığı, \%51,9'unun haftada iki gün egzersiz yaptığı, $\% 68,8$ 'inin fiziksel aktivitelerini evde yaptığı, \%48,1'inin vücut ağırlıklarında artış olduğunu ve $\% 46,8$ 'inin evde yapılan egzersizlerin yararlı olmadığ yönünde görüş bildirmişlerdir.

Pandemi Dönemi Beden Ĕ̆itimi ve Spor Yüksekokulu Öğrencilerinin Beslenme Alışkanlılan ve Fiziksel Aktivite Düzeyleri t ve Varyans Analizleri

Tablo 5. Beden Ĕ̆itimi ve Spor Yükssekokulu Öğrencilerinin Demografik Bilgilerine Göre Beslenme Alışkanlıkları ve Fiziksel Aktivite Düzeyleri t Testi Analizleri

\begin{tabular}{|c|c|c|c|c|c|c|c|c|c|}
\hline & & \multicolumn{2}{|c|}{ Beslenme } & \multirow[b]{2}{*}{$t$} & \multirow[b]{2}{*}{ p } & \multicolumn{2}{|c|}{$\begin{array}{l}\text { Fiziksel } \\
\text { Aktivite }\end{array}$} & \multirow[b]{2}{*}{$t$} & \multirow[b]{2}{*}{$\mathrm{p}$} \\
\hline & & $\bar{X}$ & Ss & & & $\bar{X}$ & Ss & & \\
\hline \multirow{2}{*}{ Cinsiyet } & Kadın & 15,97 & 4,13 & \multirow[b]{2}{*}{$-14,886$} & \multirow[b]{2}{*}{0,000} & 9,19 & 2,24 & \multirow[b]{2}{*}{$-16,514$} & \multirow[b]{2}{*}{0,000} \\
\hline & Erkek & 26,93 & 6,24 & & & 15,98 & 3,50 & & \\
\hline \multirow{2}{*}{$\begin{array}{l}\text { Beslenme } \\
\text { Eğitimi }\end{array}$} & Evet & 15,86 & 4,33 & \multirow[b]{2}{*}{$-13,833$} & \multirow[b]{2}{*}{0,000} & 9,41 & 2,67 & \multirow[b]{2}{*}{$-13,300$} & \multirow[b]{2}{*}{0,000} \\
\hline & Hayır & 26,54 & 6,36 & & & 15,56 & 3,77 & & \\
\hline \multirow{2}{*}{ Üniversite } & Bitlis & 18,18 & 5,02 & \multirow[b]{2}{*}{$-11,768$} & \multirow[b]{2}{*}{0,000} & 10,84 & 3,09 & \multirow[b]{2}{*}{$-10,750$} & \multirow[b]{2}{*}{0,000} \\
\hline & Van & 27,63 & 7,12 & & & 16,08 & 4,29 & & \\
\hline \multirow{2}{*}{ Bölüm } & Beden E. Ö & 19,29 & 6,92 & \multirow[b]{2}{*}{$-9,163$} & \multirow[b]{2}{*}{0,000} & 11,43 & 4,07 & \multirow[b]{2}{*}{$-8,606$} & \multirow[b]{2}{*}{0,000} \\
\hline & Antrenörlük & 27,40 & 6,03 & & & 15,99 & 3,73 & & \\
\hline
\end{tabular}

$\mathrm{p}<0,05$

Tablo 6. Beden Eğitimi ve Spor Yüksekokulu Öğrencilerinin Demografik Bilgilere Göre Beslenme Alışkanlıkları ve Fiziksel Aktivite Düzeyleri Varyans Analizleri

\begin{tabular}{|c|c|c|c|c|c|c|c|c|c|}
\hline & & \multicolumn{2}{|c|}{ Beslenme } & \multirow[b]{2}{*}{ F } & \multirow[b]{2}{*}{ Sig } & \multicolumn{2}{|c|}{$\begin{array}{l}\text { Fiziksel } \\
\text { Aktivite }\end{array}$} & \multirow{2}{*}{ F } & \multirow{2}{*}{ Sig } \\
\hline & & $\bar{X}$ & Ss & & & $\bar{X}$ & Ss & & \\
\hline \multirow{4}{*}{ Boy } & $150-160 \mathrm{~cm}$ & 21,83 & 8,48 & \multirow[b]{4}{*}{7,259} & \multirow[b]{4}{*}{0,000} & 12,70 & 4,94 & \multirow{4}{*}{8,403} & \multirow{4}{*}{0,000} \\
\hline & $161-170 \mathrm{~cm}$ & 19,72 & 6,19 & & & 11,62 & 3,62 & & \\
\hline & $171-180 \mathrm{~cm}$ & 23,20 & 7,65 & & & 13,60 & 4,47 & & \\
\hline & $181-190 \mathrm{~cm}$ & 26,97 & 6,77 & & & 16,18 & 4,00 & & \\
\hline \multirow{3}{*}{ Kilo } & $45-60 \mathrm{~kg}$ & 20,69 & 8,01 & \multirow[b]{3}{*}{8,799} & \multirow[b]{3}{*}{0,000} & 12,20 & 4,68 & \multirow[b]{3}{*}{10,214} & \multirow[b]{3}{*}{0,000} \\
\hline & $61-75 \mathrm{~kg}$ & 22,76 & 7,08 & & & 13,26 & 4,13 & & \\
\hline & $76-90 \mathrm{~kg}$ & 26,97 & 6,77 & & & 16,18 & 4,00 & & \\
\hline \multirow{5}{*}{$\begin{array}{l}\text { Gelir } \\
\text { Durumu }\end{array}$} & $2001-3000$ TL & 15,36 & 3,94 & \multirow[b]{5}{*}{63,206} & \multirow[b]{5}{*}{0,000} & 9,07 & 2,32 & \multirow{5}{*}{68,666} & \multirow{5}{*}{0,000} \\
\hline & $3001-4000 \mathrm{TL}$ & 24,70 & 3,95 & & & 14,00 & 1,91 & & \\
\hline & $4001-5000 \mathrm{TL}$ & 27,18 & 5,82 & & & 16,73 & 2,63 & & \\
\hline & $5001-6000 \mathrm{TL}$ & 28,63 & $\begin{array}{l}6,02 \\
6,54\end{array}$ & & & 17,25 & 3,84 & & \\
\hline & 6001 TL ve üzeri & 28,20 & 8,56 & & & 16,40 & 5,55 & & \\
\hline
\end{tabular}

$\mathrm{p}<0,05$ 
Tablo 5 ve 6 incelendiğinde araştırma grubunun; cinsiyet, boy, kilo, beslenme eğitimi, gelir durumu, eğitim gördüğü üniversite ve bölüme göre beslenme alışkanlıkları ve fiziksel aktivite düzeyleri puan ortalamaları arasında istatiksel açıdan anlamlı farklılık olduğu tespit edilmiştir $(p<0,05)$

\section{Tartışma}

Araştırmada yer alan beden eğitimi ve spor yüksekokulu öğrencilerinin pandemi döneminde beslenme alışkanlıkları değerlendirildiğinde; $\% 45,5^{\prime}$ inin beslenme alışkanlıklarında değişiklikler olduğunu, \%50,6'sının günde iki ana ögün tükettiklerini, \%63,6'sı düzenli olarak kahvaltı yaptıklarını, \%26'sının stres nedeniyle öğün atladığın, ara öğünlerde büyük çoğunluğunun kek/kurabiye/bisküvi gibi yiyecekler tükettiğini ve günlük sıvı tüketiminde azalma olduğu belirlenmiştir. Gençalp (2020) pandemi döneminde ilk ve acil yardım öğrencilerinin beslenme alışkanlıkları ve fiziksel aktivite düzeylerini incelediği çalışmada katılımcıların sağlıklı beslenme alışkanlıklarının geliştirilmesinin gerektiği ve fiziksel aktivite seviyelerinin yeterli olmadığını ifade etmiştir. Błaszczyk-Bębenek, Jagielski, Bolesławska, Jagielska, Nitsch-Osuch ve Kawalec (2020) yaptıkları çalışmada Covid-19 salgını izolasyon sürecinde Polonyalı yetişkin bireylerin beslenme alışkanlıklarında değişimler olduğunu özellikle; "konserve, et, yumurta, tatl gibi" ürünler daha sık tüketilirken, "fast-food, hazır çorbalar, enerji içecekleri gibi" ürünler daha az tüketildiğini ve vücut ağırlıklarında artış meydana geldiğini belirtmişlerdir. Garipoğlu ve Bozar (2020) Covid-19 dalgınında sosyal izolasyondaki bireylerin beslenme alışkanlıklarının araştırdığ çalışmada katılımcıların beslenme alışkanlıklarında ve yaşam tarzında olumsuz yönde değişimler olduğunu ifade etmiştirler. Ayrıca katılımcıların bu dönemde karbonhidratlı besinleri daha sık tükettiğini, çay-kahve tüketiminin arttı̆ı, uyku düzeninde değişiklikler olduğu ve fiziksel aktivite azlığından vücut ağırlığında artış olduğunu belirlemiştirler. Pellegrini Ponzo, Rosato, Scumaci, Goitre, Benso ve Broglio, (2020) Covid-19 süreci kıstlama döneminde obez bireylerin kilo ve beslenme alışkanlıklarındaki değişimleri incelediği çalışmada katılımcıların karantina başladıktan sonra beslenme alışkanlıklarında olumsuz değişimlerin yanı sıra vücut ağırlıklarında önemli ölçüde artış olduğunu belirlemiştirler.Macit (2020) yaptığı araştırmada Covid-19 salgını sonrası yetişkin bireylerin beslenme alışkanlıklarında deği- 
şimler olduğu, fiziksel aktivite seviyelerinde düşüş olduğu ve takviye kullanımının arttığını belirlemiştir. Alhusseini ve Alqahtani (2020) Suudi Arabistan'da Covid-19 salgınının yeme alışkanlıkları üzerindeki etkisini belirlediği araştırmada salgın döneminde katılımcıların beslenme alışkanlıklarının önemli ölçüde değiştiğini tespit etmişlerdir. Yapılan farklı bir çalışmada Tarkoçin, Alagöz ve Çingöz (2020) yaptıkları çalışmada okul öncesi dönem çocuklarının pandemi öncesinde duygusal veya davranışsal sorunlarının olmadığını, ancak pandemiyle beraber çocuklarda "kaygı, korku, agresif/öfkeli/saldırgan davranışlar, aşırı hareketlilik, kardeş kıskançlığı, annebabaya bağımlılık" gibi davranışların ortaya çıktığı ve ebeveynlerin pandemi döneminde çocuklarında sağlıklı beslenme algısının oluştuğunu belirlemiştirler. Kriaucioniene, Bagdonaviciene, Rodríguez-Pérez ve Petkeviciene (2020) Litvanya'daki Covid-19 karantina döneminde bireylerin sağlık davranışlarını ve vücut ağırlıklarındaki değişimleri incelediği araştırmada katılımclların kısıtlama döneminde evde normalden daha fazla yemek yediklerini, daha fazla atıştırdıklarını, evde daha sık yemek yaptıklarını, kilo alıminda artış ve fiziksel aktivite düzeyinde azalma olduğunu belirlemiştirler. Özlem ve Mehmet (2020) yaptıkları araştırmada 2020 Mart ve Temmuz aylarında yayımlanan beslenme alışkanlıkları ilgili çalışmaları incelemiş ve Covid-19 karantina sürecinin beslenme alışkanlıklarının toplumdan topluma farklılık gösterdiğini ifade etmişledir. Ayrıca karantina ve strese bağlı yemek yeme sıklığının arttığı hazır yemek tüketiminin azaldığını saptamışlardır. Ismail, Osaili, Mohamad, Al Marzouqi, Jarrar, Zampelas ve Hasan (2020) Kuzey Afrika (MENA) bölgesinde yaşayan bireylerin salgın döneminde beslenme alışkanlıkları ve yaşam biçimlerini değerlendirdiği çalışmada bireylerin normalden daha fazla öğün tükettiklerini, vücut ağırlıklarında artış ve fiziksel aktivite yapma durumlarında azalma olduğunu tespit etmişlerdir. Yılmaz, Aslan ve Unal (2020) Covid-19 pandemisinin üniversite öğrencilerinin yeme alışkanlıkları ve yiyecek satın alma davranışlarını araştırdığ çalışmada katılımcıların Covid-19 dönemi öncesine göre yiyecek tüketiminin arttığı ve gida satın alınırken hijyene daha fazla önem verdiklerini belirlemiştirler. Pandemi döneminde uzun süre evde kalınması katılımcıların beslenme alışkanlıklarını ve uyku düzenini olumsuz yönde etkilemiş olabilir.

Araştırmada yer alan beden eğitimi ve spor yüksekokulu öğrencilerinin pandemi döneminde fiziksel aktivite düzeyleri incelendiğinde; \%67,5'inin 
düzenli olarak bir fiziksel aktivite yapmadığını, \%51,9'unun haftada iki gün egzersiz yaptığını, \%68,8'inin fiziksel aktivitelerini evde yaptığını, $\% 48,1^{\prime}$ inin vücut ağırlıklarında artış olduğunu ve $\% 46,8^{\prime}$ inin ise evde yap1lan egzersizlerin yararlı olmadığını belirtmişlerdir. Öncen, Aydın ve Molla (2020) Covid-19 pandemisi döneminde sokağa çıkma sınırlaması olan ve olmayan illerde yaşayan spor bilimleri öğrencilerinin fiziksel aktivite düzeylerini belirledikleri araştırmada genel olarak pandeminin katılımcıların fiziksel aktivite düzeylerini olumsuz yönde etkilediğini belirlemiştirler. Ayrıca sokağa çıkma kısıtlaması olan illerdeki katılımcıların kısıtlama bulunmayan illerdeki katılımcllara göre fiziksel aktivite düzeylerinin daha düşük olduğunu gözlemlemiştirler. Maugeri, Castrogiovanni, Battaglia, Pippi, D'Agata, Palma ve Musumeci, (2020) İtalya'da Covid-19 salgını sürecinde fiziksel aktivitenin psikolojik sağlık üzerinde etkisini belirlediği çalışmada bireylerin salgın döneminde fiziksel aktivite yapma durumlarında azalma olduğu ve bunun sonucu olarakta bireylerin psikolojik olarak olumsuz etkilediğini belirlemiştirler. Ercan ve Keklicek (2020) yaptıkları araştırmada Covid-19 pandemi döneminde üniversite öğrencilerinin fiziksel aktivite düzeylerinin azaldığı ve katılımcıların genel olarak evde yapılabilecek egzersizlere yöneldiğini tespit etmişlerdir Qin, Song, Nassis, Zhao, Dong, Zhao ve Zhao (2020) Covid-19 salgının Çin'deki yaşam tarzı üzerindeki etkisini belirlediği araştırmada salgının bireylerin fiziksel aktivite yapma durumunu olumsuz yönde etkilediği, ekran karşısında kalma süresinin uzadığı sağlıksız ve hareketsiz bir yaşam tarzını benimsediğini tespit etmişlerdir. Yapılan farklı bir çalışmada Kanık (2020) Covid-19 pandemi döneminde evde kalma süresinin uzaması sebebiyle küresel açıdan fiziksel aktivite davranışlarında değişimler olduğunu ve özellikle bu durumun kişilerin fiziksel ve zihinsel sağlıklarını olumsuz yönde etkilediğini ifade etmektedir. $\mathrm{Bu}$ olumsuz durumun önlenmesi için ev tabanlı yapılacak egzersizlerin uygulanması hem bağışıklık sistemini güçlendirmek açısından hem de Covid-19 salgınıyla mücadele etmek için önemli olduğunu belirtmiştir. Ciddi ve Yazgan (2020) Covid-19 salgınında sosyal izolasyon sırasında fiziksel aktivite durumunun yaşam kalitesine etkisini araştırdıkları çalışmada katılımcıların büyük çoğunluğunun pandemi öncesine göre fiziksel aktivite düzeyleri açısından inaktif olduğunu tespit etmişlerdir. Tunç vd., (2020) Covid-19 salgın döneminde egzersizin yaşam kalitesine etkisini araştırdığı çalışmada egzersiz yapan bireylerin yapmayan bireylere göre yaşam kalite- 
sinin daha yüksek olduğunu tespit etmişlerdir. López-Bueno, Calatayud, Andersen, Balsalobre-Fernández, Casaña, Casajús ve López-Sánchez(2020) yaptıkları çalışmada Covid-19 salgın dönemi karantina sürecinde İspanyol bireylerin fiziksel aktivite yapma durumlarında önemli ölçüde azalma görüldügünü belirlemiştirler. Pandemi döneminde uygulanan kısıtlamaların ve karantina süreçlerinin bireylerin düzenli olarak fiziksel aktivite yapma alışkanlıklarını olumsuz yönde etkilediği düşünülmektedir.

Sonuç olarak;Covid-19 salgını sürecindeki kısıtlamalar ve karantina süreci beden eğitimi ve spor yüksekokulu öğrencilerinin beslenme alışkanlıklarında ve fiziksel aktivite düzeylerinde değişikliklere neden olduğu sonucuna ulaşılmıştır. Pandemi sürecinde bireylerin; kötü beslenme alışkanlıkları, fiziksel aktivite azlığı, uyku düzensizliği ve vücut ağırlıklarında artış olduğu belirlenmiştir. Bu durumun özellikle evde karantina önlemleri ve kısıtlamalar bağlamında sağlıklı beslenme ile düzenli fiziksel aktivitenin teşvik edilmesi ve mevcut salgın dönemlerinde kişilerin fiziksel ve zihinsel açıdan sağlığını korumada yardımcı olacağını düşünmekteyiz. 


\section{EXTENDED ABSTRACT}

\section{Determination of The Nutritional Habits and Physical Activity Levels of The Students of The School of Physical Education and Sport During the Pandemic Period \\ Ramazan Erdoğan \\ Bitlis Eren University}

Coronavirus disease (COVID-19), which the World Health Organization (WHO) considers to be a pandemic, is an important public health problem that has a serious impact on life in our country and around the world. In addition to the measures taken to control the spread of the pandemic, nutritional habits, levels of physical activity, consumer behavior, education and training methods and daily life are rapidly changing (Gençalp, 2020). The responsibility of individuals indicated to support the immune system during the outbreak of COVID-19 is to choose a healthy lifestyle, eat nutrientrich fruits and vegetables, exercise in their spare time, try to maintain a healthy body weight and sleep sufficient time (Naja \& Hamadeh, 2020). In addition, avoiding smoking and alcohol and minimizing stress are also recommended (Harvard Health Publishing Harvard Medical School, 2020). In this context, university students are also in a crucial period when their forward-looking nutritional habits are settled. It will be extremely important for students of the school of physical education and sports, who continue to live active sports lives along with university education, to eat a balanced and regular diet without skipping meals according to their body needs, both in terms of healthy life and in terms of their success in education and sports life (Yildirim et al., 2011). In this context, this research was conducted to determine the nutritional habits and physical activity levels of students of the school of physical education and sports during the pandemic period.

The research group consisted of 231 (93 women, 138 men) volunteer students with an average age of $20.26 \pm 1.34$ years studying at Bitlis Eren University (125 persons) and Van Yüzüncü Y1l University (106 people) School of 
Physical Education and Sports. The research was conducted by online survey method of data collection techniques.

Data was obtained using the survey method from participants who agreed to participate in the study after the purpose of the study was explained to the students in the research group (231 persons). The "Personal Information Form" to determine the demographic information of the participants and the questionnaire created by Yucel (2015) aimed at examining the "Nutritional Habits and Nutritional Information Levels of Health Workers" to determine their healthy lifestyle and the short form of the "International Physical Activity Survey" were adapted for the purpose of the study by taking the opinion of four experts in the field and applied to the participants in the process of obtaining the data. The validity and reliability of the survey questions used in the study were tested and the KMO value was .909 and the Crombach alpha value was 967.

$1 \mathrm{MET}=3.5 \mathrm{ml} / \mathrm{kg} / \mathrm{min}$ oxigen consumption

MET $\times 3.5 \times$ weight $(\mathrm{kg}) / 200=\ldots \mathrm{kcal} / \mathrm{min}$.

According to the physical activity score, participants ' physical activity levels were classified as "low, moderate and high". (Devran ve Saka, 2019):

- <3 MET low intensity activity,

- 3-6 MET moderate intensity activity,

- 6 MET high intensityactivity.

The data obtained in the study were processed by using the SPSS statistical package program. Demographic information of the research group, nutritional habits and physical activity levels were summarized with the help of "arithmetic mean, percentage, frequency" statistics. The "KolmogorovSmirnov" test was used for normality analysis of the data. Independent Samples $t$ and one-Way ANOVA test were applied for intra-group comparisons to the data determined to show normal distribution. The significance was accepted as $\mathrm{p}<0.05$.

It was found that there were statistically significant differences between the average score of the research group's gender, height, weight, nutrition education, income status, nutritional habits and physical activity levels according to the university and aepartment in which they studied $(\mathrm{p}<0,05)$.

It was determined that when the nutritional habits of physical education and sports college students included in the study were evaluated during the pandemic period, $45.5 \%$ of them had changes in their eating habits, 
$50.6 \%$ of them consume two main meals a day, $63.6 \%$ of them regularly eat breakfast, $\% 26$ of them skipped meals due to stress, most of them consume foods such as cake / cookie / biscuit at snacks and there is a decrease in daily fluid consumption. Gençalp (2020) examined the eating habits and physical activity levels of first and emergency aid students during the pandemic period and stated that healthy eating habits of participants should be developed and that physical activity levels were not sufficient. In their study, Błaszczyk-Bębenek et al. stated that during the isolation process of the Covid-19 outbreak, there were changes in the eating habits of Polish adults, especially while products such as "canned, meat, eggs, sweets" were consumed more often, products such as "fast food, ready-made soups, energy drinks" were consumed less, and there was an increase in body weight.

When the physical activity levels of School of physical education and sports students in the study were examined during the pandemic period, $67.5 \%$ of them did not do regular physical activity, $51.9 \%$ of them exercised two days a week, $68.8 \%$ of them did physical activity at home, $48.1 \%$ of them had an increase in body weight and $46.8 \%$ of them said that home exercises were not useful. Öncen et al. (2020) stated that in a study in which sports science students living in provinces with and without Covid-19 pandemic determined their physical activity levels, in general, the pandemic negatively affected participants ' physical activity levels. They also observed that participants in provinces with curfew restrictions had lower levels of physical activity than participants in provinces without restrictions. Maugeri et al. (2020), determined the effect of physical activity on psychological health during the Covid-19 pandemic in Italy in a study that found that individuals had a decrease in physical activity during the epidemic period, and as a result, individuals had a psychologically negative impact.

As a result, it was concluded that the restrictions and quarantine process in the Covid-19 outbreak period caused changes in the eating habits and physical activity levels of students of the school of physical education and sports. It was determined that during the pandemic, individuals had poor nutritional habits, lack of physical activity, sleep disorders and an increase in body weight. We believe that this will help to promote healthy eating and regular physical activity, especially in the context of quarantine measures and restrictions at home, and to maintain the physical and mental health of people during the current pandemic periods. 


\section{Kaynakça / References}

Alhusseini, N. ve Alqahtani, A. (2020). COVID-19 pandemic's impact on eating habits in Saudi Arabia. Journal of Public Health Research, 9(3).

Arce, M., Michopoulos, V., Shepard, K. N., Ha, Q.-C., ve Wilson, M. E. (2010). Diet choice, cortisol reactivity, and emotional feeding in socially housed rhesus monkeys. Physiology \& behavior, 101(4), 446-455. doi:10.1016/j.physbeh.2010.07.010.

Błaszczyk-Bębenek, E., Jagielski, P., Bolesławska, I., Jagielska, A., Nitsch-Osuch, A., ve Kawalec, P. (2020). Nutrition behaviors in Polish adults before and during covid-19 lockdown. Nutrients, 12(10), 3084.

Brooks, S. K., Webster, R. K., Smith, L. E., Woodland, L., Wessely, S., Greenberg, N., ve Rubin, G. J. (2020). The psychological impact of quarantine and how to reduce it: rapid review of the evidence. The Lancet, 395(10227), 912-920. doi:https://doi.org/10.1016/S0140-6736(20)30460-8.

Christ, A., Lauterbach, M., ve Latz, E. (2019). Western Diet and the Immune System: An inflammatory connection. Immunity, 51(5), 794-811. doi:10.1016/j.immuni.2019.09.020.

Ciddi, K. P., ve Yazgan, E. (2020). Covid-19 salgınında sosyal izolasyon sirasında fiziksel aktivite durumunun yaşam kalitesi üzerine etkisi. İstanbul Ticaret Üniversitesi Sosyal Bilimler Dergisi, Covid-19 Sosyal Bilimler Özel Say1s1, 262-279.

Courtin, E., ve Knapp, M. (2017). Social isolation, loneliness and health in old age: a scoping review. Health Soc Care Community, 25(3), 799-812. doi:10.1111/hsc.12311.

de Heredia, F. P., Gómez-Martínez, S., ve Marcos, A. (2012). Obesity, inflammation and the immune system. Proc Nutr Soc, 71(2), 332-338. doi:10.1017/s0029665112000092

Devran, B. S., ve Saka, M. (2019). Lise öğrencilerine verilen beslenme eğitiminin beslenme alışkanlıkları, beslenme bilgi düzeyi ve fiziksel aktivite üzerine etkisi. Beslenme ve Diyet Dergisi, 47(3), 5-14.

Ercan, Ş., and Keklicek, H. (2020). Covıd-19 pandemisi nedeniyle üniversite öğrencilerinin fiziksel aktivite düzeylerindeki değişimin incelenmesi. İzmir Katip Çelebi Üniversitesi Sağlık Bilimleri Fakültesi Dergisi, 5(2), 69-74.

Flaskerud, J.H. (2015). Mood and food. Issues Ment Health Nurs, 36(4), 307- 310. doi:10.3109/01612840.2014.962677. 
Garipoğlu, G., ve Bozar, N. (2020). Covid-19 salgınında sosyal izolasyonda olan bireylerin beslenme alışkanlıklarındaki değişiklikler. Pearson Journal Of Social Sciences \& Humanities, 6(6), 100-113.

Gençalp, D. K. (2020). Covıd-19 salgını döneminde ilk ve acil yardım öğrencilerinin beslenme alışkanlıkları ve fiziksel aktivite durumlarının değerlendirilmesi. Paramedik ve Acil Sağllk Hizmetleri Dergisi, 1(1), 1-15.

Harvard Health Publishing Harvard Medical School. (2020). How to boost your immune system. 07.11.2020 tarihinde https://www.health.harvard.edu/stayinghealthy/how-to-boost-yourimmune-system adresinden erişilmiştir.

Ismail, L. C., Osaili, T. M., Mohamad, M. N., Al Marzouqi, A., Jarrar, A. H., Zampelas, A., ve Hasan, H. (2020). Assessment of Eating Habits and Lifestyle during Coronavirus Pandemic in the MENA region: A CrossSectional Study. British Journal of Nutrition, 1-30.

Jayne, J. M., Ayala, R., Karl, J. P., Deschamps, B. A., McGraw, S. M., O'Connor, K., ve Cole, R. E. (2020). Body weight status, perceived stress, and emotional eating among US Army Soldiers: A mediator model. Eat Behav, 36, 101367. doi:10.1016/j.eatbeh.2020.101367.

Kanık, Z. H. (2020). Covıd-19 pandemisinde ev tabanlı fiziksel aktivite. Gazi Sağllk Bilimleri Dergisi, Özel Sayı, 46-51.

Kriaucioniene, V., Bagdonaviciene, L., Rodríguez-Pérez, C., ve Petkeviciene, J. (2020). Associations between Changes in Health Behaviours and Body Weight during the COVID-19 Quarantine in Lithuania: The Lithuanian COVIDiet Study. Nutrients, 12(10), 3119.

López-Bueno, R., Calatayud, J., Andersen, L. L., Balsalobre-Fernández, C., Casaña, J., Casajús, J. A., and López-Sánchez, G. F. (2020). Immediate impact of the COVID-19 confinement on physical activity levels in Spanish adults. Sustainability, 12(14), 5708.

Macit, M. S. (2020). Covid-19 salgını sonrası yetişkin bireylerin beslenme alışkanlıklarındaki değişikliklerin değerlendirilmesi. Mersin Üniversitesi Sağllk Bilimleri Dergisi, 13(3), 277-288.

Maugeri, G., Castrogiovanni, P., Battaglia, G., Pippi, R., D'Agata, V., Palma, A., and Musumeci, G. (2020). The impact of physical activity on psychological health during Covid-19 pandemic in Italy. Heliyon, 6(6), e04315.

Naja, F., ve Hamadeh, R. (2020). Nutrition amid the COVID-19 pandemic: A multi-level framework for action. European Journal of Clinical Nutrition, doi: https://doi.org/10.1038/s41430-020- 0634-3. 
Öncen, S., Aydın, S., ve Molla, E. (2020). COVID-19 pandemisi döneminde sokağa çıkma sınırlaması olan ve olmayan illerde yaşayan spor bilimleri öğrencilerinin fiziksel aktivite düzeylerinin değerlendirilmesi. Electronic Turkish Studies, 15(6), 739-749.

Özkan, A. (2017). Sinıf öğretmenlerinin ve adaylarmın enerji ve besin öğesi alımları (beslenme alışkanlikları) ile sağllklı yaşam biçimi davranışlarının ve fiziksel aktivite düzeylerinin belirlenmesi ve ilişkilendirilmesi. Yayınlanmamış Yüksek Lisans Tezi. Bartın Üniversitesi Eğitim Bilimleri Enstitüsü. Bartın.

Özkan, A. (2020). Sağlık Hizmetleri Meslek Yüksekokulu öğrencilerinin fiziksel aktivite düzeyi ve sağlıklı yaşam biçimi davranışlarının incelenmesi. Uluslararası Güncel Ĕ̆itim Araştırmaları Dergisi, 6(1), 112-126.

Özlem, A., ve Mehmet, N. (2020). Eatıng habıts changes durıng covid-19 pandemıc lockdown. ESTÜDAM Halk Să̆glı̆̆ Dergisi, 5, 188-196.

Pellegrini, M., Ponzo, V., Rosato, R., Scumaci, E., Goitre, I., Benso, A., ve Broglio, F. (2020). Changes in weight and nutritional habits in adults with obesity during the "lockdown" period caused by the COVID-19 virus emergency. Nutrients, 12(7), 2016.

Qin, F., Song, Y., Nassis, G. P., Zhao, L., Dong, Y., Zhao, C., ve Zhao, J. (2020). Physical activity, screen time, and emotional well-being during the 2019 novel coronavirus outbreak in China. International Journal of Environmental Research and Public Health, 17(14), 5170.

Swift, D. L., Johannsen, N. M., Lavie, C. J., Earnest, C. P., ve Church, T. S. (2014). The role of exercise and physical activity in weight loss and maintenance. Prog Cardiovasc Dis, 56(4), 441-447. doi:10.1016/j.pcad.2013.09.012.

Tambağ, H. (2011). Hatay Sağlık Yüksekokulu öğrencilerinin sağlıklı yaşam biçimi davranışları ve etkileyen faktörler. Hacettepe Üniversitesi Sağllk Bilimleri Fakültesi Hemşirelik Dergisi. 47-58

Tang, W., Hu, T., Hu, B., Jin, C., Wang, G., Xie, C., ve Xu, J. (2020). Prevalence and correlates of PTSD and depressive symptoms one month after the outbreak of the COVID-19 epidemic in a sample of home-quarantined Chinese university students. J Affect Disord. doi:10.1016/j.jad.2020.05.009.

Tarkoçin, S., Alagöz, N., ve Boğa, E. (2020). Okul öncesi dönem çocuklarının pandemi sürecinde (covıd-19) davranış değişiklikleri ve farkındalık düzeylerinin anne görüşlerine başvurularak incelenmesi. Electronic Turkish Studies, 15(6), 1017-1036. 
Tunç, A. Ç., Zorba, E., ve Çingöz, Y. E. (2020). Covid 19 salgını döneminde egzersizin yaşam kalitesine etkisi. Uluslararası Güncel Ĕ̆itim Araştırmaları Dergisi, 6(1), 127-135.

Vermeulen, E., Stronks, K., Snijder, M. B., Schene, A. H., Lok, A., de Vries, J. H., ve Nicolaou, M. (2017). A combined high-sugar and high-saturated-fat dietary pattern is associated with more depressive symptoms in a multi-ethnic population: the HELIUS (Healthy Life in an Urban Setting) study. Public Health Nutr, 20(13), 2374- 2382. doi:10.1017/s1368980017001550.

Yildirim, İ., Yildirim, Y., Tortop, Y., ve Poyraz, A. (2011). Afyon Kocatepe Üniversitesi Beden Eğitimi ve Spor Yüksekokulu öğrencilerinin beslenme alışkanlıkları ve bunları etkileyen faktörler. Uluslararası Insan Bilimleri Dergisi, 8(1), 1375-1391.

Yilmaz, H. Ö., Aslan, R., ve Unal, C. (2020). Effect of the COVID-19 Pandemic on Eating Habits and Food Purchasing Behaviors of University Students. Kesmas: Journal Kesehatan Masyarakat Nasional (National Public Health Journal), 15(3).

Yücel, B. (2015). Sağlık çalışanlarının beslenme alışkanları ve beslenme bilgi düzeylerinin ıncelenmesi. Y.L Tezi, Başkent Üniversitesi Sağlık Bilimleri Enstitüsü, Ankara.

\section{Kaynakça Bilgisi / Citation Information}

Erdoğan, R. (2021). Pandemi döneminde beden eğitimi ve spor yüksekokulu öğrencilerinin beslenme alışkanlıkları ve fiziksel aktivite düzeylerinin belirlenmesi. OPUS-Uluslararası Toplum Araştırmaları Dergisi, 17(Pandemi Özel Say1s1), 3276-3295. DOI: 10.26466/opus.862585 